\title{
A Dynamic Solvency Approach for Life Insurance $\dagger$
}

\author{
Rosa Cocozza, Dipartimento di Economia Aziendale \\ Università di Napoli "Federico II" \\ Emilia Di Lorenzo, Dipartimento di Matematica e Statistica \\ Università di Napoli "Federico II"
}

\begin{abstract}
The paper investigates risk management processes in life insurance, in a perspective consistent with the framework of Solvency II. The paper starts with the breakdown of the business dynamics. This analysis provides for a complete depiction of risk and value driver within life business. The corresponding map is then put into the solvability context, in order to formally identify the equilibrium conditions. Considerations about the technical equilibrium of an insurance portfolio and the financial regulation lead to a dynamic system of solvency assessment. The formal model is applied to a life annuity cohort in a stochastic context in order to exemplify the potential of the model, especially referred to the need to frame solvency assessment in a dynamic perspective.
\end{abstract}

\section{JEL classification: G22, G28}

Keywords: Life insurance, financial risk, insolvency risk, capital adequacy, financial regulation.

$\dagger$ Although the paper is the result of a common study, the first three sections are by R. Cocozza and the remaining three are by E. Di Lorenzo. 


\section{$\S 1$. Introduction}

Solvency of insurance companies has recently undergone a renewed interest not only by EC institutions and companies, facing a prudential regulation reform process ${ }^{1}$, but also by international association in a broader context, because of a project - developed by the International Accounting Standards Board (IASB) ${ }^{2}$ - to propose an accounting standard for insurance with the aim of enhancing understandability, relevance, reliability and comparability of general purpose financial reporting for insurance worldwide. Moreover, the wider discussion on capital adequacy sparked by the new Basle capital accord (BIS 2001) addresses the need for satisfactory instruments for prudential supervision of insurance companies and for consistency with other sectors, mainly that of banking. These circumstances, coupled with the persistent worldwide financial difficulties companies are facing, have given rise to a remarkable convergence of different and relevant solvency topics, involving corporate, actuarial and reporting issues ${ }^{3}$.

Within this debate, the paper addresses some methodological issues concerning the solvency of life insurance companies, with main reference to investment risk, and suggests a conceptual framework for the risk system as well as for the solvency assessment. This framework constitutes the basis for the development of a formal model for the appraisal of the technical equilibrium of an insurance portfolio, applied to a life annuity cohort in a stochastic context exclusively for the purpose of illustrating the potential of the model itself. From a critical perspective, attention is focused on both the risk system of insurance undertakings and the dichotomy between static and dynamic systems of solvency assessment, for which the discriminating factor is represented by employed as well as potentially exploitable risk indicators.

1 At the end of 2002 the European insurance legislation has been revised and updated, within a more general reform context regarding the solvency of insurance companies, known as Solvency I. This amendment preludes to a wider reform project (Solvency II), already started and aimed at reviewing the regime in the light of current development in insurance, risk management, finance techniques and financial reporting and at establishing a more effective solvency system. For details see London Working Group (2002) and KPMG (2002).

2 The IASB project started in 1997, with the objective of developing a standard capable of allowing comparisons of financial statements. The first stage of the project ended on March 2004 with the publication of the International Financial Reporting Standard 4 Insurance Contracts.

3 Among the others, see KPMG (2002); IASB (1999); Institute of Actuaries and Faculty of Actuaries (Hairs et al. 2001); International Actuarial Association (IAA 2002); International Association of Insurance Supervisors (IAIS 2000, 2002). 


\section{$\S 2$. Solvency, capital and prudential supervision}

An insurance company is solvent "if it is able to fulfil its obligations under all contracts under all reasonably foreseeable circumstances" (IAIS 2002). Nevertheless, in order to come to a practicable definition, it is necessary to make clear under which situation the appropriateness of the assets to cover claims is to be considered.

The question, referring to the valuation purposes, does not have an answer serving all, since it depends on many issues. Indeed, it is relevant whether the company is deemed as a closed operation or a going concern, thus including only written business (run-off basis) or also future new business (going-concern basis). Additionally, it depends on the aim of the evaluation that is the mere financial progress of the company or its ability to meet claims and other obligations in all but the most extreme circumstances. The first topic defines the relevant risk factors: on a going concern basis also fluctuations around the expected value of the new business will be taken into account (thus allowing for netting within different pools), while on a runoff basis only fluctuations within the single pool will be considered (thus secluding clearing). The second one defines the amplitude of the evaluation, which in probabilistic terms would correspond to the confidence level choice (from intermediate levels to extreme events).

In general, regulators could evaluate solvency on a run off basis and/or on a going concern basis, as they are both significant, although the latter approach is a more realistic depiction of the treasury, which normally nets among different pools, while the former is more prudent, given that it evaluates the equilibrium without any exogenous and tentative support from eventual business.

Therefore, solvency evaluation is a process, whose logical paradigm should sequentially consist of three main steps: relevant risk recognition, risk measurement and definition of capital requirements to absorb occurring losses. Unfortunately, the apparent ease of the procedure completely fades out when moving from the exegesis to the empirical implementation, where technical troubles couple with dealing difficulties connected to capital requirement costs borne by intermediaries and by the system. Concerning the first issue, the risk system and the relative breakdown is not always properly stated; while with reference to the second aspect, appraisal methodologies cast doubt on their effectiveness and efficiency.

\subsection{Risk recognition for life insurers}

The aim of this section is to provide a methodological insight into risk recognition and a risk analysis framework, and not a risk breakdown, since any possible risk categorization is suitable for the single purpose and none can serve all. 
In general, the main risk for a firm is that revenues prove to be unable to cover expenses. If this valuation also concerns the shareholders, the capital invested is not adequately remunerated. This might be addressed as equity risk. This very broad definition embraces all risks and provides for their measurement through the variance of the expected profit over a time bucket (risk horizon, accounting period and so on), or also over the entire duration of the business. Premiums and claims respectively are typical insurance revenues and expenses: therefore equity risk stems from the potential inequality among these elements, with the further difficulty that revenues have to be estimated before expenses because of the inverted cycle. Therefore, all the factors that can give rise to the inequality - and in fact to a loss - are crucial and define the whole risk subsystem. In this light, the difference can arise from both incorrect ex-ante setting and increased ex-post expenses, thus involving all the business functions. In other words, the divergence may be determined by the (in)ability/(un)feasibility to estimate not only pure premiums but also loadings in accordance with expenses and profits and, at the same time, by the (in)ability/(un)feasibility to keep those expenses low, with reference to both expectations and variances.

If we regard the life business on a run-off basis and concentrate only on the determinants of pure premiums, the risk system can basically be described as a matter of rates: interest and mortality. In other words, from a general point of view, life insurance business is characterized by two main risk factors: demographic and financial ${ }^{4}$. Demographic risks arise from the event that assumed frequencies can differ from actual occurrences of relevant outcomes ${ }^{5}$. Likewise, financial risks - connected with the implicit guarantee of a rate of return built in most policies - originate in the case of a divergence between the actual return on assets purchased with written premiums and the rate of interest formerly applied to premium rating.

\subsection{Risk measurement and capital requirements}

The second step in the solvency assessment is, as stated, the risk measurement phase, which should result in a fair representation of the hazards incumbent on the

4 Babbel et al. (1997) define "the risk that the firm is paying too much for the funds it receives, or alternatively the risk that the firm is receiving too little for the risks it has agreed to absorb" as the actuarial risk.

5 The IASB addresses the event that number of insured events will differ from previous expectations as occurrence risk, which is ascribed to three main factors: model (incorrect model), parameter (incorrect estimates) and process (random statistical fluctuations). The qualification could be also refined distinguishing between faults due to avoidable inaccuracy and those arising from unavoidable fluctuations. In an actuarial perspective, the occurrence risk is the insurance (or underwriting) risk. 
insurance business. The measurement system should be hence capable of stating the danger potential and able to limit it through capital requirements. In this respect the current methodologies cast some doubt on their effectiveness and efficiency and the scope of this section is mainly to focus the attention on some critical issues ${ }^{6}$.

There are essentially two main types of solvency methodologies used by supervisory authorities: fixed ratio and risk-based systems.

The fixed ratio system, including that traditionally implemented in EU countries, is a formulaic method which attempts to calculate a solvency margin requirement through a fixed percentage of a risk exposure proxy, usually a financial statement item. In the EU model for life companies, for example, the book value of the mathematical reserve is regarded as a financial risk proxy, while the amount of the non-negative capital at risk is considered an insurance risk proxy. The required solvency margin is the aggregate of a fixed percentage of the two proxies. These two proxies are reduced in value according to preset regulatory boundaries, in order to limit the reinsurance recoveries. Although very simple, inexpensive and not discretionary, this approach does have disadvantages. Apart from the relevance given only to certain types of risk (i.e. mortality risk), it does not reflect the company-specific risk profile for restricted reinsurance allowances ${ }^{7}$. In addition, the direct proportionality linked to fixed coefficients of capital requirements to reserve and capital at risk assumes that higher values of the items automatically account for higher risk exposure. This automatic procedure is to say the least naive, if not unsafe and unfair. Such a direct relationship could be tolerable if the insurance portfolio (i.e. the risk pool) did not have the essential characteristics of qualitative and quantitative homogeneity. At the same time, it is misleading if the larger reserve coincides with pools that are not only homogeneous but also very large, indeed so large that the original universe can be replicated with growing precision. Likewise, the amount of reserves is only a rough estimate of the investment risk exposure, the latter being conditional upon the assets (investments) and liabilities (reserves) mismatch and upon asset features. Hence, a capital requirement directly proportional to mathematical reserves and capitals at risk through a fixed ratio not only captures marginally the specific risk profile of the company, but can also give rise to regulatory arbitrages as well as provide incentives for under-reserving.

On the other hand, risk-based approaches are founded on an ad hoc evaluation of risk components in order to calculate capital requirements reflecting the size and overall risk exposures of an insurer. The most important of these systems is the risk-

\footnotetext{
6 For a complete comparative analysis see KPMG (2002).

7 The last directive (2002/83/EC) sets ceilings for reinsurance allowance for life assurance and annuities (15\% for mathematical reserve and $50 \%$ for non-negative capital at risk).
} 
based Capital (RBC) implemented in the US since the early nineties by the National Association of Insurance Commissioners ${ }^{8}$. The objective is to calculate a capital requirement for each of the main risks faced by insurers, which for life business are divided into asset risk, insurance risk, interest rate risk, and business risk. There is no doubt that the backing risk system is far more comprehensive than EU approach as well as that the evaluation procedure is more consistent with the specific company risk profile. To start with, the asset risk, defined as risk of default for affiliated investments and debt assets and risk of loss in market value for equity assets ${ }^{9}$, is separately detected from interest rate risk defined as the risk of losses due to changes in interest level linked to a mismatch between asset and liability cash flows ${ }^{10}$. Secondly, insurance risk (underwriting risk), referring to the excess claims from both random fluctuations and inaccurate pricing for future level of claims, is evaluated as a percentage of the capital at risk scaled by size. Finally, there is the inclusion of a wide range of general business risks faced by life insurers (business risk) set according to premium income. For each risk different factors are applied to the corresponding items on the financial information to express the risk potential as likely loss. Effects of portfolio aggregations and correlation among various types of risk are considered - but not truly measured by a covariance adjustment, adding together items that are believed to be correlated, so that what is left are groups of risk items believed to be substantially not correlated to each other. The covariance adjustment then squares these resulting groups, adds the resulting squares together and takes the square root of the sum of the squares. Finally, the $\mathrm{RBC}$ is calculated as the sum of the total risk net of the covariance adjustment.

Both methods, although different in calculus, have an analogous theoretic background, which is very similar to the banking approach. Once some estimate of the potential loss has been set, a capital requirement is derived from, in the attempt more or less formalized to keep the ruin (i.e. insolvency) probability within a level

8 Canada implements a similar system denoted as Minimum Continuing Capital and Surplus Requirement.

9 Off-balance sheet items (non-controlled assets, derivative instruments, guarantees for affiliates and contingent liabilities) are included in this risk component. All insurance companies are subject to an asset concentration factor that reflects the additional risk of high concentrations in single exposures.

10 The factors in this calculation represent the surplus necessary to provide for a lack of synchronization of asset and liability cash flows. The impact of interest rate change is greatest on those products where the guarantees are most in favor of the policyholders and where the policyholder is most likely to respond to changes in interest rates by withdrawing funds from the insurer. Therefore, risk categories vary by the withdrawal reserve (i.e. whether there is substantial penalty for withdrawal). 
reckoned acceptable by the system. The level of the formalization, that is to say the adopted valuation model, does make the difference. In this respect, the two methods are quite similar, since in both cases the potential loss is not truly estimated, but only determined by parameters inferred from observation of relevant contexts. Therefore, the level of capital required, also for supervisory intervention, is set according to a pragmatic definition of solvency along with inductive method ${ }^{11}$.

As an alternative, there is the possibility of building up a complete distribution of the company's results and then of the probability of ruin under a deductive methodology, capable of setting a formal relationship between capital requirements and ruin probabilities. This probabilistic approach, more complex but also more accurate, has two main forms: simulation-based and analytical. The simulation-based approach attempts to cover the full range of risk variables sampled from statistical distribution in a simulation procedure, considering a wide range of outcomes, likelihood of adverse development and interaction of risk variables. Nevertheless, the result of successive trials does not really have to replicate the very probability distribution itself. Rather, the distribution is completely modelled in the analytical approach according to stochastic processes that are able to replicate the driving dynamics of the model. Naturally, these deductive methodologies have many evident advantages, since they produce output that is relevant and meaningful (Babbel et al. 1998, 2002; Hairs et al. 2001; KPMG 2002) and, last but not least, they are consistent with the Basle approach, by virtue of being actually internal models, whose effective application should, of course, be conditional upon a validating procedure.

\section{$\S 3$. A framework for the equilibrium appraisal}

Risk recognition is functional to risk measurement and sets its boundaries: the relevance of a risk push towards some measurement system. To this end, it is opportune to revise the condition of the equilibrium for a life insurer, enlightening the relevant risk factors.

Let us proceed along the chronological and logical sequence of the insurance undertaking. The first hazard of the core business stems from the quality of the inferential process and, therefore, from the eventual discrepancies between future and actual expenses the insurer has to bear. The first difficulty is clearly related to the case of actual pertinent occurrences higher than the original estimated frequencies, which could give rise to a significant paucity of available assets, reflecting an inadequate

11 These approaches benefit also from scenario-analysis, that are projections of the company's financial statement, with the end of modelling the whole performance under different conditions and imposing a capital level adequate to the possible scenarios (mainly to the worst case). 
evaluation of technical reserves. Likewise, there would be a scarcity of available assets, should the actual rate of return be lower than the assumed interest rate. Therefore, the two conditions have similar relevance and strength and reflect the two main risk factors of the life-insurer business, since every changing parameter in a pricing formula is a risk factor.

For example, let us consider the premium $(P)$ for an immediate temporary $(n)$ unitary annuity

$$
P=\sum_{r=1}{ }_{r} p_{x} e^{-\int_{0}^{r} \bar{\delta}(s) d s}
$$

where $\bar{\delta}(s)$ is the instantaneous rate of interest observed at the beginning of the business, and ${ }_{r} p_{x}$ is the probability of surviving $r$ years after attaining age $x$.

Formula (1) implies that the final equilibrium (time $n$ ) of a cohort of $c$ identical policies is constrained by

$$
c P e^{\int_{0}^{n} \delta(s) d s}-\sum_{r=1}^{n} N^{x}(r) e^{\int_{r}^{n} \delta(s) d s} \geq 0
$$

where $\delta(s)$ is the instantaneous total rate of return ${ }^{12}$ on assets purchased with written premiums observed at the end of the business, and $N^{x}(r)$ is the actual number of survivors at age $x+r$.

Formula (2) computes the result of the portfolio, that is to say what actuaries would qualify as surplus, accountants as income, and economists as profit. If it proves positive, the business produced benefits and, of course, losses, if negative, while the null level sets the minimal equilibrium (i.e. insolvency threshold).

By virtue of (1), inequality (2) can be rewritten as

$$
\sum_{r=1}^{n} e^{\int_{r}^{n} \delta(s) d s}\left[c_{r} p_{x} e^{\int_{0}^{r} \delta(s) d s} e^{-\int_{0}^{r} \bar{\delta}(s) d s}-N^{x}(r)\right] \geq 0
$$

which holds at least if

$$
\left[\int_{0}^{r} \delta(s) d s-\int_{0}^{r} \bar{\delta}(s) d s\right]-\left(\ln \left(N^{x}(r)\right)-\ln \left(c_{r} p_{x}\right)\right) \geq 0 .
$$

In this case the minimal equilibrium is directly dependent on the single period differentials between the integral of the instantaneous total return on assets purchased with written premiums and that of the original interest rate, and between the logarithm of the actual number of survivors and the expected number of survivors. The result (2)

12 As Parker (1997c) states very clearly this rates encompasses interest income, capital gains and losses. 
will exhibit a surplus (deficit) - and eventually a profit (loss) - whenever formula (4) is positive (negative) for any combination of the four relevant variables, the result being equal to the single period difference capitalized at the rate of return on asset for the residual duration of the policy as shown by formula (3).

Naturally, many dynamics can simultaneously contribute to the differentials that depend on risk factors linked to both the assets in which premiums are invested and the value of liabilities for which capitalized premiums are deferred. Together with the demographic dynamic, the most important factor is the nature of the assets: if these are financial, the risks faced will be mainly financial, ${ }^{13}$, they will depend directly on the asset type and will not have any autonomous relevance. Besides, the crux of the problem is the difference between the total rate of return on assets and the rate of interest originally applied in premium calculation, so that it can be precisely addressed as investment risk, in order to highlight the composite nature of relevant risk drivers. At the same time, other factors can contribute to the difference such as the quality of the risk management process, with reference to both diversification and risk pooling 14. This implies that the level of the result and its variability is strictly dependent on individual company elements that involve both exogenous and endogenous factors ${ }^{15}$.

In order to gain an insight into the driving factors of the result, let us analyse its time stratification. At the end of the first period the equilibrium is given by the ability of the written premiums invested for one year to cover both the current claims and the present value of future outflows (mathematical reserve), that is

$$
c P e^{\int_{0}^{1} \delta(s) d s}-N^{x}(1)-N^{x}(1) \sum_{r=1}^{n-1}{ }_{r} p_{x+1} e^{-\int_{1}^{r+1} \bar{\delta}(s) d s} \geq 0 .
$$

This relation is able to express at the same time the equilibrium on the balance sheet and on the income statement, since it is capable of focusing the attention on the operating income, which in our restricted case is what really drives the change in the net worth $(W)$. As a matter of fact, written premiums plus investment income (first term of

13 Financial risk is the risk of a possible future change in one or more of a specified interest rate, security price, commodity price, foreign exchange rate, index of prices or rates, a credit rating or credit index or similar variable. Logically, also in this case it would be possible to distinguish model, parameter, and process, as for occurrence risk.

14 Of course, the managerial areas and the risk factors involved will be more numerous as we move from pure premium to office premiums, that is to say from a restricted to a complete analysis of the business.

15 As a consequence, the risk assessment system should be able to evaluate also the specific risk components, that is to say should be based on internal models. 
(5)) minus claims (second term) are the liability-driven assets, the final reserve (third term) is the corresponding liability so that the difference is the capitalized net worth (cf. Figure 1). At the same time written premiums net of the final reserve are the earned premiums, which together with the investment income and the incurred claims measure the operating income on an accrual basis (cf. Figure 2).

Similarly at the end of the second period the equilibrium is given by

$$
\left.\left[c P e^{\int_{0}^{1} \delta(s) d s}-N^{x}(1)\right)\right] e^{\int_{1}^{2} \delta(s) d s}-N^{x}(2)-N^{x}(2) \sum_{r=1}^{n-2}{ }_{r} p_{x+2} e^{-\int_{2}^{r+2} \bar{\delta}(s) d s} \geq 0
$$

that once again can be interpreted as a static condition of equilibrium on the balance sheet and as a dynamic condition of equilibrium on the income statement and can be divided into the capitalized result on the first period plus the result on the second period.

Similarly for the year $t$ the general expression for the equilibrium condition is

$$
\begin{gathered}
{\left[c P e^{\int_{0}^{t} \delta(s) d s}-\sum_{r=1}^{t-1} N^{x}(r) e^{\int_{r}^{t} \delta(s) d s}\right]-} \\
-\left[N^{x}(t)-N^{x}(t) \sum_{r=1}^{n-t}{ }_{r} p_{x+t} e^{-\int_{t}^{t+r} \bar{\delta}(s) d s}\right] \geq 0
\end{gathered}
$$

while at the end of the business (time $n$ ) the result is given by the compact formula (2), from which it can be inferred that the result depends on the return on the assets along the whole period and on the income accrued in each period. Therefore, solvency is properly the ability to comply with these non-negative relationships and can be formally expressed as the probability of respecting permanently, that is to say, in each period, the general equilibrium condition expressed by

$$
\begin{gathered}
\mathcal{P}\left(\left[c P e^{\int_{0}^{t} \delta(s) d s}-\sum_{r=1}^{t-1} N^{x}(r) e^{\int_{r}^{t} \delta(s) d s}\right]-\right. \\
\left.-\left[N^{x}(t)-N^{x}(t) \sum_{r=1}^{n-t}{ }_{r} p_{x+t} e^{-\int_{t}^{t+r} \bar{\delta}(s) d s}\right] \geq 0\right)=1-\epsilon
\end{gathered}
$$

Hence, inequality (7) expresses the equilibrium simultaneously from business and actuarial perspective and can be used for prudential regulation if a probability level for its non negative value can be set (formula (8)). The level of this probability is a political question and sets the level of the capital adequacy, which actually refers to a margin adequate to keep the probability of insolvency within a limit which is considered 
bearable, with reference to both capital costs borne by the intermediaries and the risk level faced by policyholders.

This framework, which is of course a minimal breakdown of the risk system faced by life-insurers, has the advantage to enlighten some fundamental logical and methodological issues:

a) negative elements of the insurer portfolio, that is to say technical reserves, are exposed to typical risk factors stemming from the quality of the inferential process (modelling risk, longevity risk, interest rate risk); these risk factors, definable as liability risk drivers, lead to an increase in the technical reserves higher (lower) than that previously stated and arise from an increase (decrease) in the expected monetary value of the contingent liability (insurance risk) and/or from a decrease (increase) in the discount rates applied for the reserve evaluation ${ }^{16}$;

b) positive elements of the insurer portfolio, that is to say investments corresponding to reserves, are exposed to risk factors stemming from the selected type of investments (market risks); these risk factors, addressable as asset risk drivers, give rise to actual revenues lower (higher) than those expected and come from a decrease (increase) in the investment income (investment proceeds, value readjustments, realization values);

c) the blend of assets and liabilities with returns not perfectly (positively) correlated yields an addendum to the portfolio variance that is substantially dependent on the correlation among the risk factors influencing both sides of the balance-sheet. These risk factors, that can be labelled as portfolio additional risk drivers, give rise to a lower or higher technical account balance (income statement result) than expected.

It follows that the basic risk system can be divided into two main groups: the nondiversified risks associated with holdings of assets and liabilities ${ }^{17}$ and the additional risks for portfolio mix (i.e. individual variances, portfolio weights and correlation coefficients). Therefore, whenever there are similar risk factors influencing both positive and negative elements, the effect produced by those factors on the net value of the portfolio will differ from the effect produced on the components if the correlation among risk factors is not perfect. This implies that interest rate fluctuations affect both the

16 In the EU regulations there are two main options: the first refers to a kind of market rate because of the reduction carried out under the European rules governing the market rate in order to obtain the technical rate; the second refers to a discount rate depending on the yield of company assets. Neither of the options is in line with the current IASB projects; in the exposure draft for insurance contract it is stated that the "starting point for determining the discount rate for insurance liabilities and insurance assets should be the pre-tax market yield at the balance sheet date on risk-free assets".

17 The term nondiversified applies here to the two sides of the balance sheet regarded as singular components of a two-asset portfolio, although they can originate from a proper diversification strategy. 
investment income and the change in the technical reserves, but their impact does not necessarily offset if the elasticity of the relevant values is not identical and/or if the value of the positions is not perfectly balanced. In other words, if the yield curve is not flat, (7) becomes

$$
\begin{gathered}
c P \prod_{h=0}^{t-1} r(h, h, h+1)-\sum_{k=1}^{t-1} N^{x}(k) \prod_{h=k}^{t-1} r(h, h, h+1)- \\
-N^{x}(t) \sum_{k=1}^{n-t}{ }_{k} p_{x+t} \prod_{h=0}^{k-1} v(t, t+h, t+h+1)-N^{x}(t) \geq 0,
\end{gathered}
$$

where $v(x, y, z)$ is the value at time $y$, quoted at time $x$, of a contract which guarantees a monetary unit at time $z$. For every fixed value of $x$ and $y, v(x, y, z)$, considered as function of $z$, gives the term structure of prices at time $y$ of contracts underwritten at time $x$. If $y>x$, we have the forward term structure; if $y=x$ we have the spot term structure. Consistently $r(x, y, z)=1 / v(x, y, z)$.

As a result, there is at least from a theoretical perspective the potential for an increase in the technical reserves arising from a decrease in the rates applied for the evaluation not offset by a net positive effect in the investment income. This is the case when the elasticity of the reserve and that of the connected investments are not perfectly matched, as well as when the corresponding market values are different. The impact of the hazard will be, then, enhanced or relieved by correlation and by spread between the total return on investments and the rate applied in the reserve evaluation and by the time stratification of this departure. In other words, would the relevant rate be the same for both sides of the balance-sheet also with reference to their respective duration, there really would be the scope (rationale) for analyzing a unique risk factor which would impact on the net value of the position. Nevertheless, a variety of regulatory constraints, such as the investment rules or accounting prescriptions ${ }^{18}$, force the two sides of the balance to be exposed to different risk factors also with reference to duration. Therefore, there is a different impact of the interest rate risk on the asset and liability portfolio - and on the firm performance - which is conceptual different from the solely variation of the investment income. There is therefore both the theoretical opportunity and the

18 Italian regulation, for example, sets a complex system of ceilings for asset allocation. Therefore, portfolio selection is strongly biased and even deceived whenever the overall asset weights, fixed by law, prevent from picking the optimal investment portfolio for the single cohort of policies. Therefore, as a paradox, investment rules could generate a sub-optimal allocation, thus giving rise to counterintuitive results. Similarly, the regulatory prescription concerning the rate of interest to be applied in the reserve evaluation could generate some optical illusions about the income that can be distributed. 
practical scope for evaluating the technical equilibrium of the portfolio with reference to both components under a properly deductive methodology.

\section{$\S 4$. An alternative model}

In this section we present a model for evaluating and quantifying insolvency in the case of a portfolio of life policies.

The methodological bases are set in the study of the cumulative probability distribution function of the portfolio reserve; in fact knowing the upper tail of such distribution allows the actuary to estimate if the value of his future obligations exceeds the programmed reserve funds.

The mathematical scenario, in which the insolvency problem is framed, provides an analytical methodology, apt to a strict approach to solvency assessment. This is even more useful, once we recall that the recent actuarial literature shows that the insolvency problem is not always analyzed properly by simulation techniques or scenario testing methodologies, since vagueness of the precision levels, long simulation times and interlocutory results of empirical checkings do not allow to implement significant tests ${ }^{19}$.

\subsection{Notations and preliminary results}

Let us consider a portfolio of $c$ identical $n$-year temporary life annuity-immediate, each policy being of 1 unit payable at the end of each year while the life aged $(x)$ survives. Let $T_{i}(x)$ be the random variable representing the future lifetime of the $i$-th insured (for every $i$ ).

The prospective loss at time $t$, for the $i$-th policy, is defined as the difference ${ }_{t} L^{(i)}$ at time $t$ between the present value of future benefit payments and the present value of future premium payments, assuming that $T_{i}(x)>t$.

Let $K_{i}(x)$ denote the curtate future lifetime of $(x)$, that is the random variable representing the number of complete future years lived by $(x)$ in $[0, n-x]$.

Then

$$
{ }_{t} L^{(i)}=\sum_{j=1}^{K_{i}(x+t)} e^{-\int_{t}^{t+j} \delta(s) d s},
$$

19 Parker (1997b) compares three methodologies (tractable model, stochastic simulation, scenario testing) to investigate the ruin probability for a portfolio of life insurance contracts with or without reinsurance: simulations reveal themselves not easily replicable "by other actuaries and regulatory authorities" and need long running times to obtain a sufficiently acceptable approximate distribution; on the other hand scenario testing causes underestimation of the insolvency risk. 
where $\delta(s)$ is the force of interest.

As well known, the net premium reserve at time $t$ is defined as the conditional expectation of ${ }_{t} L^{(i)}$, given that $T_{i}(x)>t$.

Let us denote by ${ }_{t} \mathbf{L}$ the prospective loss for the entire portfolio. In particular, if $N^{x}(t)$ is the number of survivors at time $t$ in the cohort of the $c$ insureds aged $x$ at issue, it holds

$$
{ }_{t} \mathbf{L}=N^{x}(t) \sum_{r=1}^{n-t}{ }_{r} p_{x+t} e^{-\int_{t}^{t+r} \delta(s) d s},
$$

or, by an equivalent notation,

$$
{ }_{t} \mathbf{L}=\sum_{r=1}^{n-t} c_{t+r} e^{-\int_{t}^{t+r} \delta(s) d s} \mid K_{i}(x)>t,
$$

$c_{t+r}$ being the number of survivors at time $t+r$.

In the following we consider the random variable ${ }_{t} \mathbf{L} / c$, representing the average reserve per policy, for which the following result holds.

Theorem 4.1. Let the random variables $K_{i}(x)$ be independent and identically distributed and independent on the variables $\delta(s)$; then, when the total number of policies at issue tends to infinity, ${ }_{t} \mathbf{L} / c$ converges in distribution to the random variable

$$
{ }_{t} \boldsymbol{\Lambda}={ }_{t} p_{x} \sum_{r=1}^{n-t}{ }_{r} p_{x+t} e^{-\int_{t}^{t+r} \delta(s) d s}
$$

Proof: Considering the definition (10), it is easy to observe that $N^{x}(t)$ is a binomial random variable, which assumes the values $0,1, \ldots, c$, each life insured having the same probability ${ }_{t} p_{x}$ of surviving until the age $x+t$.

Since

$$
\lim _{c \rightarrow \infty} \mathcal{P}\left(\left|\frac{N^{x}(t)}{c}-{ }_{t} p_{x}\right| \geq \epsilon\right)=0
$$

we deduce that $\left(\frac{N^{x}(t)}{c}-{ }_{t} p_{x}\right) \sum_{r=1}^{n-t}{ }_{r} p_{x+t} e^{-\int_{t}^{t+r} \delta(s) d s}$ converges in probability to zero, because $E\left[\sum_{r=1}^{n-t} r p_{x+t} e^{-\int_{t}^{t+r} \delta(s) d s}\right]<\infty$. Then ${ }_{t} \mathbf{L} / c$ converges in distribution to ${ }_{t} \boldsymbol{\Lambda}$.

It is possible to prove the proposition also considering the definition (11) for the reserve, and observing that $c_{t+r}$ is a binomial random variable, hence

$$
\lim _{c \rightarrow \infty} \mathcal{P}\left(\left|\frac{c_{t+r}}{c}-{ }_{t} p_{x} r p_{x+t}\right| \geq \epsilon\right)=0 .
$$

Remark 4.2. The random variable ${ }_{t} \boldsymbol{\Lambda}$ approximates the average reserve at time $t$, in the case of a very large portfolio. In this scenario the pooling effect related to 
the random deviations of the number of deaths comes true, so the insurance risk can be neglected, while the financial risk plays a fundamental role in the global portfolio riskiness 20 .

\subsection{Insolvency measures}

In our notation, for every fixed value of $t, y(u)$ represents the force of interest accumulation function, that is

$$
y(u)=\int_{t}^{t+u} \delta(s) d s, \quad u \geq 0 .
$$

For a fixed set $E$ we indicate by $\chi_{E}$ its characteristic function, that is

$$
\chi_{E}(x)=\left\{\begin{array}{ll}
1 & \text { if } x \in E \\
0 & \text { otherwise }
\end{array} .\right.
$$

Following a methodology proposed by Parker (1994) and successively extended by Coppola et al. (2003) in the case of life annuity portfolios, we get the following result

Proposition 4.3. Let us consider the random variable $\Psi_{m}=\sum_{i=1}^{m}{ }_{i} p_{x+t} e^{-y(i)}$. If $\{\delta(t)\}_{t \in \mathbf{N}}$ is a Gaussian process, the distribution function of $\Psi_{m}$ is expressed by the formula:

$$
F_{\Psi_{m}}(z)=\int_{-\infty}^{\infty} g_{m}(z, y) d y
$$

where

$$
g_{m}(z, y)=\int_{-\infty}^{\infty} f_{y(m)}(y \mid y(m-1)=s) g_{m-1}\left(z-{ }_{m} p_{x+t} e^{-y}, s\right) d s
$$

with

$$
g_{1}(z, y)=\chi_{\left\{\zeta: \zeta \geq p_{x+t} e^{-y}\right\}}(z) f_{y(1)}(y),
$$

$f_{y(s)}$ being the probability density function of $y(s)$.

Proof: Let us set

$$
g_{m}(z, y)=P\left(\Psi_{m} \leq z \mid y(m)=y\right) f_{y(m)}(y)
$$

where $f_{y(m)}$ is the density function of $y(m)$. Then, the distribution function of $\Psi_{m}$ is given by

$$
F_{\Psi_{m}}(z)=\int_{-\infty}^{\infty} g_{m}(z, y) d y
$$

\footnotetext{
20 Obviously the demographic changes (mortality/survival) are very important in the case of small portfolios; moreover in a wider perspective the mathematical model could incorporate also other risk factors, such as lapsation, expenses, taking into account possible relationships between lapse rates and rates of return.
} 
In order to evaluate the integral on the right hand side of (15), we consider a numerical procedure proposed by Parker (1994) and (1997a) and revised by Coppola et al. (2003).

In particular, by using known properties of conditional density functions, we get

$$
\begin{gathered}
g_{m}(z, y)=P\left(\Psi_{m} \leq z\right) f_{y(m)}\left(y \mid \Psi_{m} \leq z\right)= \\
=P\left(\Psi_{m-1} \leq z-{ }_{m} p_{x+t} e^{-y}\right) f_{y(m)}\left(y \mid \Psi_{m-1} \leq z-{ }_{m} p_{x+t} e^{-y}\right)= \\
=P\left(\Psi_{m-1} \leq z-{ }_{m} p_{x+t} e^{-y}\right) \times \\
\times \int_{-\infty}^{\infty} f_{y(m)}\left(y \mid y(m-1)=s, \Psi_{m-1} \leq z-{ }_{m} p_{x+t} e^{-y}\right) \times \\
\times f_{y(m-1)}\left(s \mid \Psi_{m-1} \leq z-{ }_{m} p_{x+t} e^{-y}\right) d s
\end{gathered}
$$

Finally, remembering formula (14) and the markovian property of the process $\{y(t)\}$, we can write

$$
\begin{gathered}
g_{m}(z, y)=\int_{-\infty}^{\infty} f_{y(m)}\left(y \mid y(m-1)=s, \Psi_{m-1} \leq z-{ }_{m} p_{x+t} e^{-y}\right) \times \\
\times g_{m-1}\left(z-{ }_{m} p_{x+t} e^{-y}, s\right) d s= \\
=\int_{-\infty}^{\infty} f_{y(m)}(y \mid y(m-1)=s) g_{m-1}\left(z-{ }_{m} p_{x+t} e^{-y}, s\right) d s
\end{gathered}
$$

Moreover, if $m=1 \Psi_{1}=p_{x+t} e^{-y(1)}$ and, by virtue of (5),

$$
\begin{gathered}
g_{1}(z, y)=P\left(\Psi_{1} \leq z \mid y(1)=y\right) f_{y(1)}(y)= \\
=P\left(p_{x+t} e^{-y(1)} \leq z \mid y(1)=y\right) f_{y(1)}(y) .
\end{gathered}
$$

Then we obtain

$$
g_{1}(z, y)=\chi_{\left\{\zeta: \zeta \geq p_{x+t} e^{-y}\right\}}(z) f_{y(1)}(y)
$$

On the basis of Proposition 4.3, once we observe that

$$
{ }_{t} \boldsymbol{\Lambda}={ }_{t} p_{x} \Psi_{n-t},
$$

we can state the following result involving the distribution function of ${ }_{t} \boldsymbol{\Lambda}$. 
Corollary 4.4. Under the hypotheses of the Proposition 4.3, the distribution function $H_{t} \boldsymbol{\Lambda}$ of ${ }_{t} \boldsymbol{\Lambda}$ is given by

$$
H_{t} \mathbf{\Lambda}(u)=F_{\Psi_{n-t}}\left(\frac{u}{{ }_{t} p_{x}}\right) \text { for every } u \in \mathbf{R}
$$

\section{$\S 5$. The stochastic interest rate}

In order to present a possible scenario for the force of interest in the period under consideration, we assume that the dynamic in time of such rate is described as the sum of two components (cf. Di Lorenzo et al. 1999)

$$
\delta(t)=r(t)+X(t)
$$

$r(t)$ is a deterministic component obtained on the basis of the current relevant rates $^{21}$; $X(t)$ is a stochastic component representing any deviation phenomenon. In particular we suppose that $\{X(t): 0 \leq t<+\infty\}$ is an Ornstein-Uhlenbeck process, with parameters $\beta>0$ and $\sigma>0$, and initial position $X(0)=0$, involved by the following stochastic differential equation

$$
d X(t)=-\beta X(t) d t+\sigma d W(t)
$$

where $W(t)$ is a standard Wiener process.

Then the discounting process is given by

$$
\phi(0, t)=e^{-\left(\int_{0}^{t} r(s) d s+\int_{0}^{t} X(s) d s\right)},
$$

$e^{-\int_{0}^{t} X(s) d s}$ being log normally distributed with parameters $-E\left[\int_{0}^{t} X(s) d s\right]$ and $\operatorname{var}\left[\int_{0}^{t} X(s) d s\right]$, with

$$
\begin{gathered}
E\left[\int_{0}^{t} X(s) d s\right]=0 \\
\operatorname{var}\left[\int_{0}^{t} X(s) d s\right]=\frac{\sigma^{2}}{\beta^{2}} t+\frac{\sigma^{2}}{2 \beta^{3}}\left[-3+4 e^{-\beta t}-e^{-2 \beta t}\right] .
\end{gathered}
$$

21 Choosing a particular model for the the interest rate is naturally dependent on the aim of the evaluation process: anyway the model proposed overcomes the difficulties connected to the choice of the mathematical model depicting the evolution in time of the interest rate, since it is flexible and suitable to the a large class of models, i.e. the markovian ones. 
As it is well known the autocovariance function of the stochastic discounting process is given by

$$
\begin{gathered}
\operatorname{cov}\left[e^{-\int_{0}^{h} X(s) d s}, e^{-\int_{0}^{k} X(s) d s}\right]= \\
=e^{\frac{1}{2}\left[\operatorname{var}\left[\int_{0}^{h} X(s) d s\right]+\operatorname{var}\left[\int_{0}^{k} X(s) d s\right]\right]}\left[e^{\operatorname{cov}\left(\int_{0}^{h} X(s) d s, \int_{0}^{k} X(s) d s\right)}-1\right] .
\end{gathered}
$$

\section{$\S$ 6. A numerical example}

Now, on the basis of Corollary 4.4, we can calculate the cumulative distribution function of ${ }_{t} \Lambda$ in $t=15$ in the case of a portfolio of $n$-temporary life annuities with $n=17$, each policy being issued to a person aged $x=50^{21}$. We fix a constant deterministic component $r=0.09$, and the parameters $\beta=0.11, \sigma=0.005$ for the stochastic component. The results are collected in Table 1.

The table shows the behaviour of the upper tail of the distribution of ${ }_{15} \Lambda^{22}$. For instance, for a fixed average reserve equal to 1.7576, the insolvency occurs with probability $5.11 \%$. In other words, the value at time $t$ of the insurer's future obligations (that is the value at time $t$ of the insurer's debt position) is greater than the programmed reserve fund with probability $5,11 \%$.

\section{$\S 7$. Conclusions and future research lines}

The article focuses on the complex and composite solvability problem for a life insurance business. At first, after an overview of the risk map, it displays the crucial role of an accurate measurement of the various risk components, in light of the relevant implications in calculating the solvency margin, as well as the not trivial connections with the prudential supervision.

From our survey of the main methodologies currently adopted by supervisory authorities in solvency assessment, the need arises to base the risk measurement system on a strict definition of the distribution of the company's results, in order to deduce, by means of tractable models, parameters indicative of (in)solvency.

Against this background, an innovative analytical methodology has been formalized, largely because of its formal foundation with respect to simulative and/or scenario testing procedures. We have shown that it is possible to obtain probability distributions of main parameters related to an insurance policy portfolio. The methodology has

\footnotetext{
21 We assume the survival/mortality probabilities reported in the Italian Mortality Table 1981-Male.

22 The results are performed by means of Mathematica.
} 
been applied to the reserve of a life insurance portfolio, more precisely to a temporary life insurance portfolio cohort, to delineate the potential involved in the model. In particular, the upper tail of the distribution of the portfolio reserve has been deduced, thus obtaining rigorous estimates of the insurer's capacity to face his future obligations, in a scenario involving volatility of interest rates.

The above model could give rise to many different applications and future research lines. At first, it is not constrained by the choice of a specific stochastic process, but it can be usefully adopted with a large class of processes and can be calibrated with diverse parameters. In this context an interesting future issue, which is beyond the scope of this paper, might be the evaluation of different regulatory regimes aimed at assessing the corresponding probability of insolvency. Furthermore, from a more practical perspective, the discrepancy between accounting solvency and economic solvency could be investigated. For example, the analysis of various results, connected with diverse processes and parameters describing the interest rate dynamics, could be regarded as a measure of the inequality between the book value and the current value of the intermediation portfolio. Finally, the model could be extended to non-homogeneous portfolios by inserting the correlations among common risk drivers.

Some other areas of interest could be explored. The most important, which will be studied in future researches, concerns whether there is a significant quantitative inequality between the use of a simulation-based model or the adoption of an analytical approach. The answer to this question is of course conditional upon the choice of consistent "measures", that is to say of consistent scenarios, so as to guarantee a more meaningful comparison. 


\section{References}

Babbel, D.F., Gold, J., Merrill, C.B., 2002. Fair value of liabilities: the financial economics perspective. North American actuarial journal 6 (1), 12-27.

Babbel, D.F., Merrill C.B., 1998. Economic valuation models for insurers. North American actuarial journal 2 (3), 1-17.

Babbel, D.F., Santomero, A.M., 1997. Risk management by insurers: an analysis of the process. Journal of risk and insurance 64, 231-270.

Berger, A.N., Herring, R.J., Szego, G.P., 1995. The role of capital in financial institutions. Journal of banking and finance 19, 393-430.

BIS Basle Committee on Banking Supervision, 2001. The new Basle capital accord. BIS, January.

Cocozza, R., 2000. La gestione del rischio di tasso di interesse nelle assicurazioni del ramo vita. CEDAM, Padova.

Coppola, M., Di Lorenzo, E., Sibillo, M., 2003. Stochastic Analysis in Life Office Management: Applications to Large Annuity Portfolios. to appear on Applied Stochastic Models in Business and Industry 19, pp. 31-43.

Di Lorenzo, E., Sibillo, M., Tessitore, G., 1999: A Stochastic Model for Financial Evaluations. Applications to Actuarial Contracts. Applied Stochastic Models in Business and Industry 15, pp. 269-275.

Girard, L.N., 2000. Market value of insurance liabilities: reconciling the actuarial appraisal and option pricing methods. North American actuarial journal 4 (1), 31-62.

Elton, E.J., Gruber, M.J., 1992. Optimal investment strategies with investor liabilities. Journal of banking and finance 16, 869-890.

Hairs, C. J., Belsham, D. J., Bryson, N. M., George, C. M., Hare, D. J. P., Smith, D. A, Thompson, S., 2001. Fair valuation of liabilities. Institute of Actuaries and Faculty of Actuaries, November.

IAA Solvency Working Party, 2002. Report of solvency working party prepared for IAA Insurance Regulation Committee. IAA, February.

IAIS Solvency \& Actuarial Issues Subcommittee, 2000. On solvency, solvency assessments and actuarial issues. IAIS, March.

IAIS Solvency \& Actuarial Issues Subcommittee, 2002. Principles on capital adequacy and solvency. IAIS, January. 
IASB Steering Committee, 1999. Insurance issue paper. IASB, December.

Knight, K., 2000. Mathematical Statistics. Chapman \& Hall/CRC, Boca Raton, Florida.

KPMG, 2002. Study into the methodologies to assess the overall financial position of an insurance undertaking from the perspective of prudential supervision. European Commission, May.

London Working Group, 2002. Prudential supervision of insurance undertakings (Sharma Report). Conference of insurance supervisory services of the member states of the EU, December.

Melsa, J.L., Sage, A.P., 1973. An Introduction to Probability and Stochastic Processes. Prentice-Hall, New Jersey.

Parker, G., 1994. Limiting Distribution of the Present Value of a Portfolio. Astin Bulletin 24, No. 1, pp. 47-60.

Parker, G., 1997a. A Portfolio of Endowment Policies and its Limiting Distribution. VIII International Symposium on Applied Stochastic Models and Data Analysis, Anacapri, pp. 67-75.

Parker, G., 1997b. Insolvency Risk: Tractable Model, Simulation and Scenario Testing. Technical Report.

Parker, G., 1997c. Stochastic analysis of the interaction between investment and insurance risks. North American actuarial journal 1 (2), 55-84.

Vanderhoof, I.T., Altman E.I., (eds.) 1998. The fair value of insurance liabilities. Kluwer Academic Publishers, Boston. Dordrecht, London. 
Table 1.

\begin{tabular}{|l|l|}
\hline \multicolumn{2}{|c|}{ Cumulative distribution function of ${ }_{15} \boldsymbol{\Lambda}(u)$} \\
\hline$u$ & $F_{t} \boldsymbol{\Lambda}$ \\
\hline 1.6524 & 0.615223 \\
1.6888 & 0.649850 \\
1.7171 & 0.676409 \\
1.7401 & 0.831008 \\
1.7576 & 0.948881 \\
1.8595 & 0.981749 \\
1.9161 & 1.000000 \\
\hline
\end{tabular}




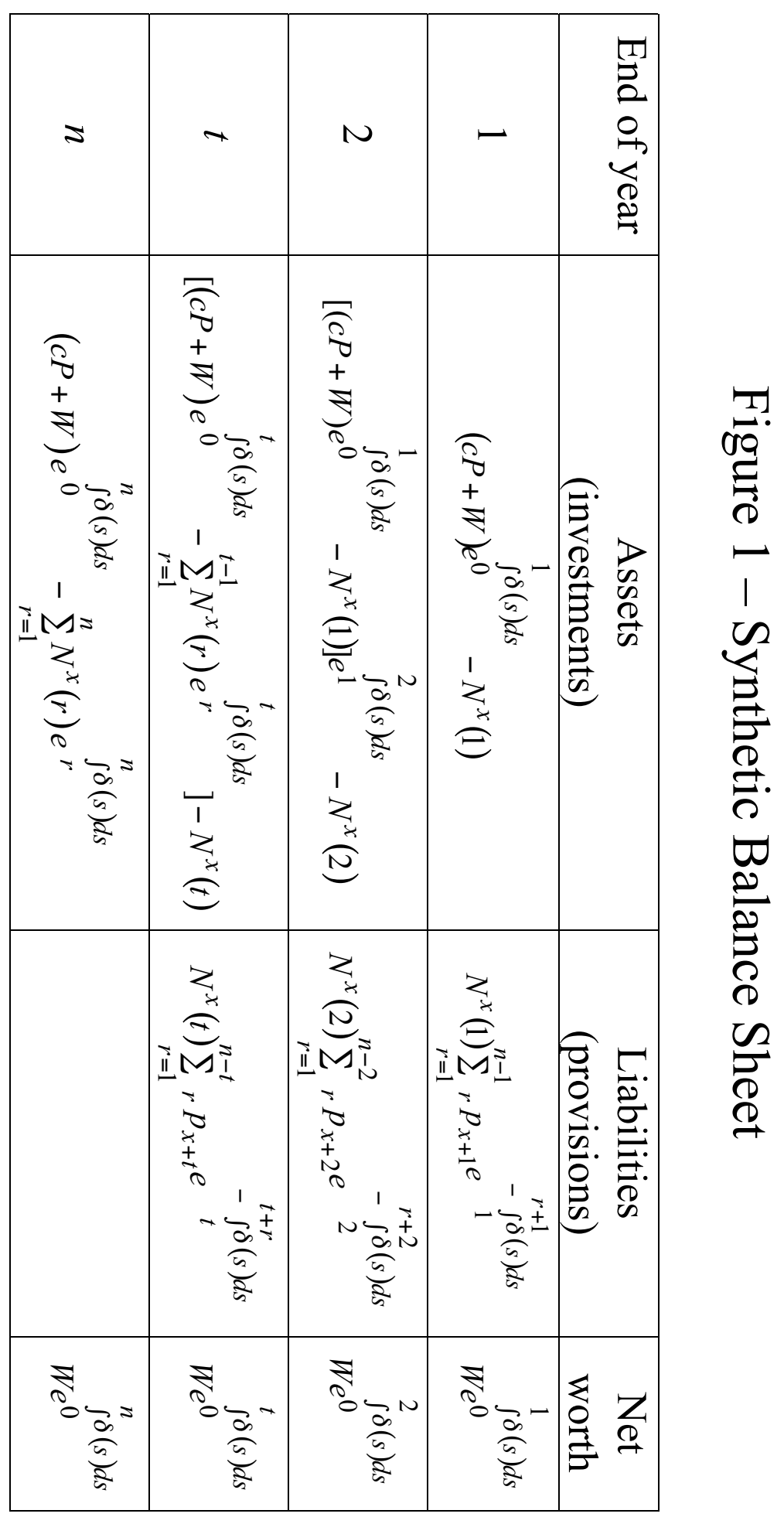




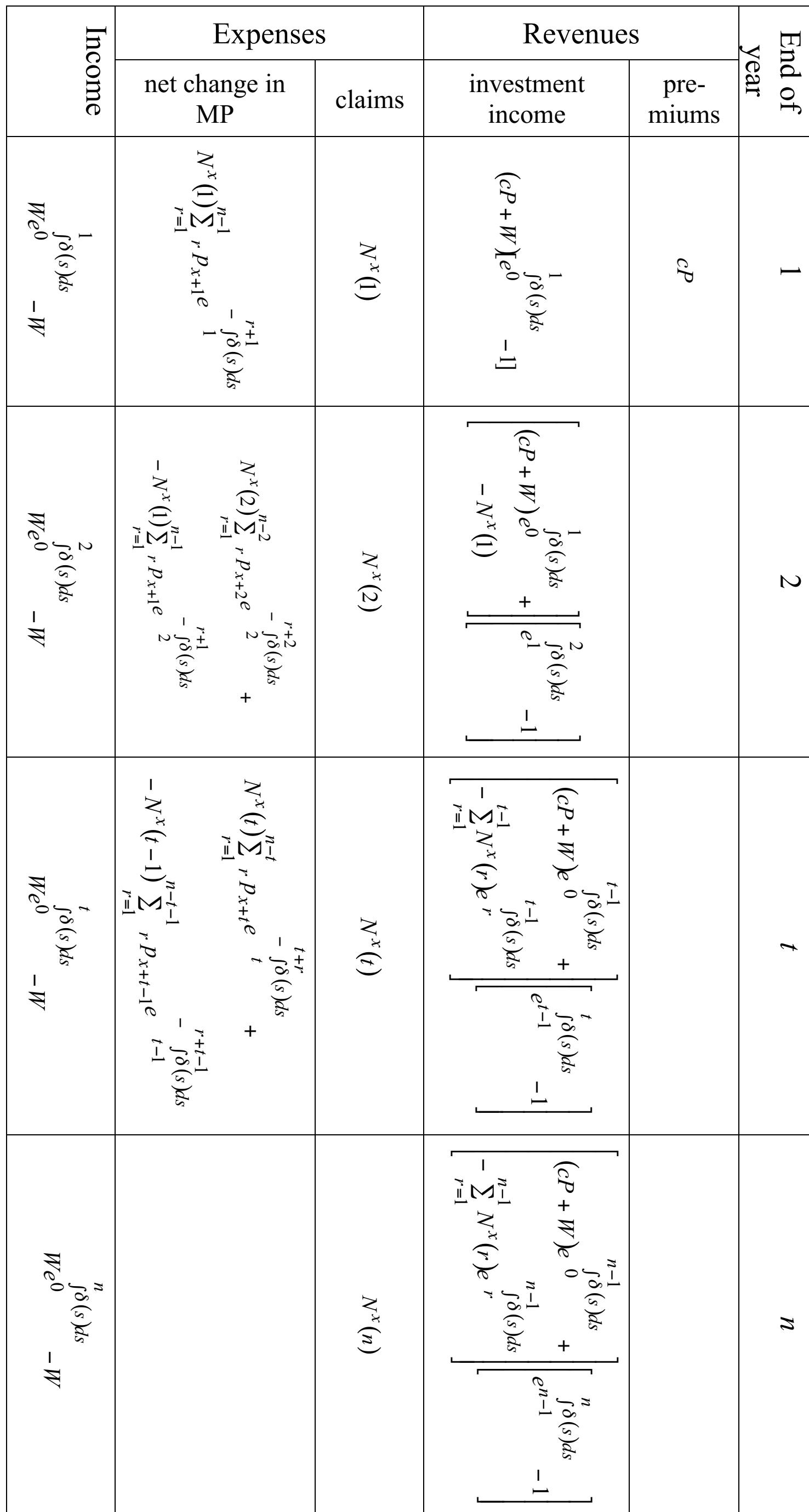

